\title{
Study on the Evaluation System of Flipped Classroom Teaching in Colleges and Universities
}

\author{
Ang ZHAO ${ }^{1}$, Chang-an SUN ${ }^{2, *}$ \\ ${ }^{1}$ Teaching Affairs Office, Nanjing University of Economics and Finance, Nanjing, China \\ ${ }^{2}$ Suzhou University of Science and Technology, Jiangsu, China \\ ${ }^{*}$ Corresponding author
}

Keywords: Evaluation Framework; Open Online Courses; Flipped Classroom.

\begin{abstract}
With the rise and development of open online courses such as SPOC and MOOC, more and more researchers are paying attention to how to carry out the practice of flipping class and make use of information technology to innovate teaching methods. Based on the analysis of flipped classroom teaching mode and curriculum evaluation theory, this paper explores the problems and solutions in the evaluation of flipped classroom teaching.
\end{abstract}

\section{Present Situation of Flipped Classroom}

As students' individual needs and self-learning abilities are increasingly concerned, it is becoming more and more important to return to the essence of teaching, which is helpful to improve students' learning enthusiasm, autonomy and individuality, and promote the development of their knowledge, ability and accomplishment. The flipped classroom teaching can be regarded as a model of contemporary classroom teaching model. In China, this teaching mode not only reverses the classroom, but more importantly, it integrates SPOC and MOOC with traditional classroom teaching to explore mixed teaching in classroom environment. On the one hand, it can make use of information technology effectively. On one hand, it stimulates students' learning motivation and enhances their learning experience.

Bloom's taxonomy of educational objectives is the theoretical basis for the reform of flipped classroom teaching mode. According to the classification of educational goals, in flipped classroom teaching, students' learning process that can be carried out independently, such as knowledge and comprehension, is achieved outside class, while the teaching process which requires teachers' guidance and participation, such as application, analysis, and synthesis, is conducted in class. Compared with traditional teaching methods, the premises of this teaching mode are that, firstly, students have to learn systematically and independently outside class; secondly, teachers need to efficiently organize students to conduct interactive learning in class. Therefore, there are two major advantages: firstly, it can give full play to students' initiative and creativity in learning; secondly, it can mobilize the interaction between teachers and students.

In 2014, Zhejiang Gongshang University made an attempt of the school-scale flipped classroom teaching. It is one of the earliest universities in China to promote the flipped classroom teaching mode at the school level. In early 2017, in order to promote the reform of teaching method, improve students' enthusiasm, autonomy and personalized learning, Nanjing University of Finance and Economics launched the teaching reform of flipped classroom. So far, flipped teaching has been fully implemented in the courses. There are some difficulties as follows. First of all, the mode of "teaching first and learning later", which reverses the traditional mode, has been widely applied in foreign universities and domestic primary and secondary school teaching design, but it is not widespread in domestic universities, especially in large class teaching. Therefore, there are few cases to learn from in the implementation process. In addition, flipped classroom requires students to complete direct learning outside the class, and the class time is strategically used for collective or personalized activities. Students who participate in the teaching reform of flipped classroom have virtually increased their extra-curricular learning time, but this can not improve their test scores accordingly, 
thus students have little enthusiasm in classroom participation. What's more, flipped classes is not a fixed process for teachers. In order to improve the effect of flipped classroom teaching, teachers are required to adjust teaching strategies in each chapter to help students achieve personalized learning, so teachers will have heavy workload. Moreover, for managers, flipped classroom differs from the traditional classroom in the teaching quality evaluation, evaluation methods, etc. Managers need to change their ideas and management methods.

\section{Theoretical Support for Flipped Classroom Evaluation: Value-pluralism Curriculum Evaluation System}

American evaluation experts Guba and Lincoln divided the curriculum evaluation into four periods. The first is measurement period represented by Thorndike. It focuses on efficiency, and systematic and standardized measurement. The second is descriptive period represented by Tayler. It is emphasized that, in the evaluation process, educational outcomes should be compared with predetermined objectives, and the key is to determine the operational behavioral objectives. The evaluation theory in the third period believes that evaluation is the process of value judgment. Evaluation is not just describing the outcome according to the objective. It also needs value judgment in the process of predetermining and realizing the objectives.

However, since the 1980 s, evaluators have gradually realized that the evaluation theories of the first three periods emphasized the objectivity and standardization of evaluation, but ignored the subjectivity, creativity, and unpredictability of the evaluation process. With the wide application of anthropological research methods in education and the importance attached to the sociocultural background of the curriculum, Guba and Lincoln believed that the significance of evaluation lied in service based on the criticism of excessive scientism and managerialism. They proposed that the entire evaluation program (premise, theory, program, effect, problem, etc.) should be thoroughly studied under the framework of responsive constructivism, so evaluation was a process of subjective participation, democratic consultation and active construction.

At present, curriculum evaluations in many countries are based on the third and fourth period theories and the CIPP evaluation model is taken as a framework. They not only focus on the summative and diagnostic function, but also on the formative function of evaluation. Combining qualitative and quantitative evaluation, the requirements of stakeholders involved in the evaluation are the starting point of the evaluation activities. In the process of evaluation, the distinctive evaluation mode and system are co-constructed through consultation.

Most of the university curriculum evaluations in China are the objective model represented by Tayler, which are mainly based on diagnosis, with the purpose of summative evaluation, ignoring the rationality of the selection and implementation of objectives. Besides, evaluation is conducted by a few authoritative experts or administrative leaders, with less participation of teachers. Furthermore, curriculum evaluation is almost regarded as classroom evaluation. The teaching effect and the quality of teachers are evaluated through observation of classes by supervisors and leaders, and peer and student's evaluation, which ignores the evaluation of curriculum construction objectives and implementation process.

In fact, teachers, students, managers, and administrators related to teaching activities should be the subject of curriculum evaluation, because its main function is to revise and improve the curriculum in addition to examining the teaching results.

\section{Curriculum Evaluation Framework of Flipped Classroom and Characteristics}

"Evaluation reform in curriculum reform has been a fundamental issue that cannot be avoided. The consistency between the theory and practice of evaluation reform substantially influences the effective advancement of reform" [1]. In any teaching reform, curriculum evaluation cannot be avoided. The same is true for the reform of flipped classroom teaching model. Different from basic education curriculum, university curriculum should put aside the selection function of curriculum 
evaluation and place "reform and promotion of teaching" in a more important position. Curriculum evaluation is defined as "the examination, analysis and evaluation of research in teaching theory, which refers to the examination of teaching effect, i.e., a concept in teaching sense or teaching category, not in selection sense" [2].

The first is the multiple purposes of evaluation. The purpose of traditional classroom evaluation or even teaching evaluation is to identify the level of students' speech, intelligence, logic and other abilities by testing their mastery of basic knowledge and skills. Flipped classroom teaching evaluation aims to realize the development of curriculum construction, students and teachers. It can be said that multiple evaluation contents, means and subjects are used to realize multiple teaching evaluations.

Taking the attendance rate as an example, in terms of the students' individual development, their self-discipline, learning attitude and learning habits can be evaluated. In terms of teachers' development, the feasibility of teaching methods, the teaching attitude and teachers' responsibility can be evaluated. In terms of curriculum development, the practicality of teaching content, the universality of teaching design and the rationality of teaching objectives can be evaluated. In addition, taking process evaluation as an example, from the perspective of students' personal development, various process evaluations in each stage can help them know their learning situation and shortcomings. Through the results of process evaluation, they reflect on themselves to correct learning attitudes, adjust learning plans and strategies, and develop their self-learning abilities. From the perspective of teachers' professional development, teachers can summarize the existing problems through process evaluation, and improve the ability of curriculum management. From the perspective of curriculum development, the rationality of teaching design and the practicality of teaching content can be examined, thus to adjust the curriculum design and content in time to enhance the attractiveness of curriculum.

Besides, the evaluation method is multiple. Traditional teaching evaluation is mostly summative evaluation. Formative evaluation and diagnostic evaluation are often neglected. It cannot evaluate teachers' teaching, students' learning and curriculum validity objectively and comprehensively. Flipped classroom teaching mode integrates process evaluation, diagnostic evaluation and summative evaluation in online learning, online homework, online discussion, classroom performance, chapter assignments and essay, mid-term and final exams to ensure that teachers comprehensively examine students' learning effects and attitudes, communication skills, and their practical and innovative abilities, etc. So the personalized development of students has been given attention. It facilitates students' self-recognition, evaluation, summarization, and correction of their own learning methods, their understanding of knowledge, and their problem-solving abilities.

Moreover, the evaluation subject is multiple. Multi-subject evaluation system participated by teachers, students, peers, supervisors, and even companies can better ensure the scientific, reasonable and objective evaluation results. Students' evaluation of teaching helps arouse their enthusiasm and initiative in learning, so as to realize students' lifelong learning and development. At the same time, the subject of student evaluation is also diversified. Students can participate in mutual evaluation and self-evaluation, so as to learn from each other. Peer evaluation and teachers' self-evaluation are beneficial for teachers' reflection on their teaching performance to make a progress. Through supervisor's evaluation, the classroom teaching effect can be objectively evaluated, as well as the rationality and scientificity of curriculum teaching design.

\section{Solutions in the Evaluation of Flipped Classroom Teaching}

To reform the teaching mode of flipped classroom, an important way is to build the corresponding evaluation and examination system, highlight the role of evaluation in improving teaching practice and promoting the development of teachers and students, thus to establish a diversified, process-oriented and developmental curriculum evaluation system. It is difficult to arouse the enthusiasm of teachers and students in the traditional dual evaluation system of students' evaluation of teaching and teachers' marking which determines students' achievements. In fact, on the one hand, 
it is necessary to establish a new curriculum evaluation system. On the other hand, there exists the original curriculum evaluation which is the same as the teaching evaluation aiming at selection in basic education.

Firstly, people's ideas need to be renewed. Traditional classroom teaching is dominant, and class time is controlled by the teacher, regardless of the student's knowledge and curriculum requirements. In addition, each student has his own learning rhythm. "No matter what rhythm I set for them, they will follow their own rhythm" [3]. However, with the deepening of the reform of flipped classroom teaching mode, educators need to constantly improve and optimize the teaching process, carefully design the teaching content, and make full use of classroom practice, so as to transform the classroom into a place that meets the individual needs of students.

For students, flipped classroom requires them to increase their learning initiative and pertinency outside class. The traditional learning mode of instilling knowledge in the classroom cannot adapt to the new teaching form. In flipped classroom, most students are not ready, even "a lot of students feel angry at me and think that I am no longer their teacher" [4]. Actually, students are full of emotion, will and interests in the learning process. If teachers fail to pay attention to that in time, it will directly affect students' mastery of knowledge and skills and the development of intelligence. In traditional teaching, the incentive function of evaluation has been neglected. Flipped classroom teaching mode is to better develop the student's personality. Therefore, the teaching evaluation should motivate students to give full play to their initiative from the aspects of emotion, will, and interests.

Secondly, it is necessary to construct a system of multiple curriculum evaluations. It should reflect the realization of teachers' classroom teaching objectives through scientific and comprehensive evaluation of the curriculum, so that teachers can improve their teaching methods and teaching design and enhance the teaching quality. Through the evaluation, students know their current learning situation, so that they can adjust their learning attitude in time, improve learning methods, and enhance their learning efficiency.

Through the flipped classroom teaching, the traditional mode of "class-examination" has been transformed to "self-learning with online tutorship and testing-classroom discussion, answering questions and practice — offline tutorship - examination". It breaks through the constraints of time and space in traditional courses and satisfies the needs of multiple learning levels. It also requires teachers to continuously improve teaching design, update teaching content, so as to guide students to conduct self-learning, self-construction, and self-management.

Thirdly, the implementation of the evaluation should avoid formalism. The multi-evaluation system aims to find the problems in teaching, and make some adjustments to improve teaching and learning, thus to enhance the professional quality of teachers, and promote the individual development of students through multiple, scientific and reasonable evaluations. Teaching management departments, teachers, and students should correctly understand the importance of teaching evaluation, correct their attitudes, and grasp the intention of the multi-evaluation system to ensure the realization of teaching evaluation objectives. It should avoid formalism that, in the process of self-evaluation and mutual evaluation, the subjects of teaching evaluation have invalid participation and favoritism, resulting in unfair evaluation results. In fact, it is impossible to investigate students' abilities and teachers' teaching quality in an all-round way. On the contrary, it brings more extra work to teachers, students, peers, and supervisors and even leads to their criticisms which will affect teaching and learning effect.

\section{Acknowledgement}

This research is a phase achievement of first project funded by the Evaluation Committee of Higher Education of Jiangsu Province. 


\section{References}

[1] Q.L., Yang. Curriculum Evaluation: A Dilemma in the Curriculum Reform. Theory and Practice of Education, Vol. (4), 2005, pp. 44-46.

[2] C.S., Wang. Jiao Xue Lun Gao. Beijing: People's Education Press, 1985.

[3] Jonathan Bergmann and Aaron Sams. Tr. Y.L., Wang. Flipped Learning: Gateway to Student Engagement. Beijing: China Youth Press, 2016.

[4] L.X., Hao and Y.D., She. On the Implication of Flipped Classroom for China's Contemporary Curriculum Reform. Comparative Education Review, Vol. (5), 2015, pp. 80-85.

[5] X., Song. Practice and Exploration of Classroom Teaching Reform in Peking University from the "Student-centered" Perspective. China University Teaching, Vol. (11), 2015, pp. 27-30.

[6] Q., Long and Kate Scantlebury. An analysis of the evaluation and strategy of Undergraduate Teaching Quality at the University of Delaware in America. Modern University Education, Vol. (5), 2015, pp. 61-69. 